\title{
Carl Ferdinand von Arlt, Ritter von Bergschmidt (1812-1887): A Pioneer in Ophthalmology
}

\author{
Konstantinos Laios ${ }^{1}$, Antonis Charalampakis ${ }^{2}$, Evangellos Mavrommatis ${ }^{3}$, \\ Konstantinos Manes ${ }^{3}$, Efstathia Lagiou ${ }^{4}$, Pavlos Lytsikas - Sarlis ${ }^{3}$, Marilita M. Moschos ${ }^{1}$
}

${ }^{1}$ First Ophthalmological Department, Medical School, National and Kapodistrian University of Athens, Greece, ${ }^{2}$ Lieutenant colonel, Dental Surgeon, 401 Army General Hospital of Athens, Greece. ${ }^{3}$ Surgical Department, "Konstantopoulio" General Hospital, Athens, Greece, ${ }^{4}$ Ophthalmological Department, General Hospital of Aigion, Aigion, Greece

Correspondence:

konstlaios@gmail.com

Tel.: + 306947091434

Fax.: + 302103474338

Received: 3 May 2019; Accepted: 25 November 2019

\begin{abstract}
Carl Ferdinand von Arlt, Ritter von Bergschmidt (1812-1887) was a pioneer in ophthalmology. The purpose of our paper is to highlight his scientific work. He did not only introduce new surgical techniques and invent new instruments in ocular surgery, but also influenced the development of ophthalmology in the $19^{\text {th }}$ century. He was an excellent and reputable professor of ophthalmology, and his students became very respected figures in ophthalmology.
\end{abstract}

Key Words: Carl Ferdinand von Arlt $\cdot$ Ocular Surgery - Innovations • Famous Students.

\section{Introduction}

Carl Ferdinand von Arlt, Ritter von Bergschmidt (1812-1887) is considered one of the most important figures in ophthalmolo- gy from the $19^{\text {th }}$ century (Figure 1 ). He had a high reputation among scholars, not only as an innovative ocular surgeon, but also as an excellent researcher, whose achievements influenced the development of ophthalmology. He was an excellent and renowned professor of ophthalmology, and his students became very respected figures in ophthalmology.

The purpose of our paper is to highlight his scientific work.

\section{Short Biography}

Carl Ferdinand von Arlt was born in Horní Krupka Obergraupen, Bohemia, on April $18^{\text {th }}$ 1812. He was the son of an Austrian blacksmith. He attended elementary and high school in Leitmeritz, where he met his future wife, the daughter of his physics teacher. $\mathrm{He}$ initially studied theology, but from 1833 to 1839 he studied medicine at the Karl-Ferdinand-Universität, University of Prague. On $30^{\text {th }}$ November 1839 he was appointed Doctor of Medicine and Surgery, and then Master of Arts in Ophthalmology. From 1840 to 1842 he was assistant to Johann Nepomuk Fischer (1777-1847) at the Ophthalmological Clinic of Prague. Until 1843 he was an intern at the Krumauer Kreisphysikate.

After the death of Fischer's assistant in the spring of 1844, von Arlt became an administrator at Fischer's clinic. In 1845 he 


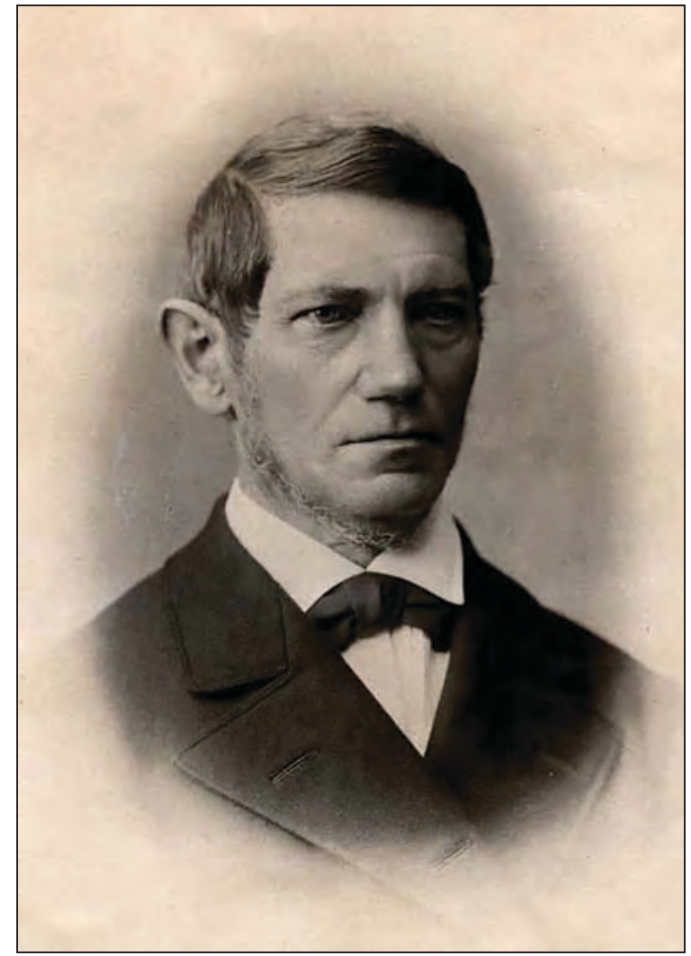

Figure 1. Carl Ferdinand von Arlt, Ritter von Bergschmidt (1812-1887). Source: Von Arlt F and Becker O. Meine Erlebnisse (My Experiences). Wiesbaden; Bergmann: 1887 p. X).

qualified in ophthalmology, and in 1847 in pathological anatomy. From 1846 to 1849 he was Associate Professor in the department specializing in diseases of the eye at the University of Prague, and from 1849 to 1856 he was Full Professor in the same department. In 1856 he moved to the University of Vienna, where he taught as Professor of Ophthalmology, succeeding Anton von Rosas (1771-1855), until his retirement in 1883. After he retired he worked as a private ophthalmologist until his death due to senile gangrene on 7th March 1887. He had three children, two daughters, and a son who also became an ophthalmologist (1).

\section{Publications}

Arlt was a prolific writer and his publications had a significant influence on other physicians worldwide. Among his works, his important treatises on various fields of ophthalmology stand out. His doctoral thesis was presented in 1839 at the University of Prague under the title: 'Von Arlt F. Dissertatio inaug, medica sistens historias Amauroseos e vitiis organicis cerebri quatuor adnexis similibus, quotquot innotuere autorum varior. Observationibus. Pragae: Haase' (Dissertation on Diseases of the Brain, Observations by the author (2). In 1846 he published his study: 'Care for the eyes in healthy and diseased conditions, with a note on eye glasses' which received an updated edition in 1868 (3). In this study he expressed the idea that the physician should himself perform the refraction, not leaving this assignment to opticians. His main treatise was 'Eye diseases for practical physicians' in three volumes, with the first published in 1850 , the second in 1853 and the third in 1856 (4). In 1876 he published his study, 'About the causes and origins of short-sightedness' (5) and in 1881, 'Clinical presentation of diseases of the conjunctiva, cornea and dermis, then the iris and ciliary body' (6). In 1875 he published the study, 'About eye injuries, with particular reference to their judicial appraisal' (6), which had a French (7) and an English (8) translation. From 1855 he became joint editor of Friedrich Wilhelm Ernst Albrecht von Graefe's (1828-1870) 'Archiv für Ophthalmologie (Ophthalmology Archives)'. In this series his most celebrated work was his 'Operationlehre', Graefe-Saemisch, 'Handbuch der gesamten Augenheilkunde (Handbook of collected Ophthalmology)', Vol. Ill, Part 2, Leipzig, 1874. He published numerous articles in various journals such as: 'Anzeiger der k. k. Gesellschaft der Ärzte in Wien (Board of the Society of Physician of Vienna),' 'Mitteilungen des Vereines der Ärzte in Niederösterreich (Communications of the Association of Physicians in Lower Austria)', 'Prager Medizinische Wochenschrift (Prague Medical Weekly), Prager Vierteljahresschrift (Prague quarterly), Wiener 
Medizinische Wochenschrift (Vienna Medical Weekly), Zeitschrift der k. k. Gesellschaft der Ärzte (Journal of the Society of Physicians)' (1).

\section{Innovations in Ophthalmology}

Arlt presented many innovations in ocular surgery and ocular clinical practice. It is important to remember that ophthalmologists still perform ocular surgeries according the surgical techniques Arlt introduced in order to treat trichiasis and pterygium. However, surgical techniques have become less traumatic today. Enucleation to treat serious endophthalmitis or an incurable painful eye remains an unpleasant surgical procedure, and Arlt's enucleation technique is still in use. In 1859 he proposed a method for enucleation of the eye. In this operation a strabismus hook it is not used, as was advised at the time after the introduction of Ferral-Bonnet's enucleation method, but an incision on the conjunctiva is made two to three millimeters behind the limbus, which is slightly retracted. The surgeon first intersects the lateral and then the medial rectus but leaving a small stump on the bulb to serve as a handle. After a cross section of the superior and the inferior rectus muscles is made, the bulb is pulled horizontally by the clamp to either the inner or outer canthus, and the scissor blades are inserted above the rear portion of the sclera to the optic nerve, which is transected with the scissors near the sclera. The bulb is pulled toward the rectus muscles, which have not been transected. The insertion of the oblique is cut, as the vessels and nerves in the posterior part of the bulb are also cut. Finally, the insertion of the last rectus muscle is performed together with the overlying conjunctiva from the sclera (9).

Arlt also proposed a method for medial tarsorrhaphy. According to his method a narrow strip of skin is resected from around the inner canthus, with the surgeon paying attention not to traumatize the underlying canaliculi, and the edges of this wound are spliced by fine sutures. After a few days the sutures are removed (10).

Another form of surgery he developed was the Jaesche-Arlt operation for trichiasis. He further developed a basic operation which was introduced by Georg Emanuel Jaesche (1815-1876). As described by Wood, in this operation: "An intermarginal incision is made along the whole length of the lid, following the gray line on the free border. This incision should be 3 or $4 \mathrm{~mm}$. in depth, and should be so placed that all the lashes will be in the anterior layer, which is separated from the tarsus. A fold of skin is next removed from the anterior surface of the lid in the following manner. An incision is made in the skin parallel to the free border and about $4 \mathrm{~mm}$ from it; above this and joining it at each end, there is made a curved incision through the skin, which marks out a crescentic area of skin that at its widest part at the middle of the lid is about $8 \mathrm{~mm}$. This crescentic piece of skin is then dissected off with blunt pointed scissors or a scalpel, care being taken not to buttonhole it, and not to remove the subjacent fibers. The gap produced by the excision of this piece of skin is then closed by five or six sutures. The sutures are not cut off, but are drawn upwards to cause the cilia border to take its new position higher up on the tarsus, and are secured to the forehead over the brow by an adhesive strip..." (11).

Arlt's method for excision of pterygium was considered one of the cleanest methods for treatment of this ocular pathology. According to his method, a Graefe knife and broad-toothed forceps are used. The neck of the pterygium is grasped by the forceps and cut by the knife. Then the pterygium bed is cut by small, straight, blunt-pointed scissors. Two incisions are made with the scissors at the upper and lower margins of the pterygi- 
um. Two others are made, starting from the end of previous two, also using the scissors, following the median line near canthus on the conjunctiva. A quadrilateral piece of the pterygium is thus removed, leaving a similar area of the sclera to be covered by the conjunctiva drawn from above and below. A cut is made under the conjunctiva, in order to avoid tension, and the wound is stitched (11).

Furthermore, Arlt's surgery for treatment of symblepharon was the most common in use after its introduction. According to this method, a portion of the adhesion is grasped with sharp-toothed forceps and dissected using a keen-edged scalpel. Instead of forceps a double-armed suture may be used. The adhesion is abscised from the globe by blunt curved scissors, and the scar tissue is also removed by two incisions made from its apex to its base. Then the flap is stitched with sutures passing out through the entire thickness of the lids, which are tied over a small roll of gauze or piece of rubber tubing. The bulbar wound is stitched with silk sutures (10).

Arlt also modified epicanthus or rhinorraphy surgery. He excised the two semilunar pieces of integument comprising the greater portion of the epicanthal folds themselves. Sometimes he also excised a flap, making a median ellipse from the nose. The sutures had an X-shaped form. This operation is also known as lateral rhinorraphy (10).

His innovations in ocular surgery were not limited to new surgical techniques, but he also introduced new surgical instruments. Arlt's scalpel is a modification of the general surgeon's scalpel, having an elongated blade with a central point. The scalpel is 3.5 centimeters long and at its greatest width 5 to 6 millimeters. This scalpel could be used in various operations, giving the surgeon great flexibility, because it could create a pouch at its point, cut and be inserted to the orbit or the bulb at many angles.
Arlt also introduced a new loop for extraction of the lens during a cataract operation. His loop is elongated and has teeth in order to facilitate grabbing the lens, whereby the teeth make it more secure, and to ease the insertion of the instrument due to its elongated form. However, his best known instruments are the iris scissors. He invented this instrument for excising a piece of occluding pupillary membrane and the iris attached to it. After the initial incision using a keratome, the instrument is inserted into the anterior chamber, and when the blades are opened the iris diaphragm is located between the two blades. Firm pressure is exerted and the diaphragm is punched out. Therefore the instrument has blades like scissors for iridectomy, with a 45 degree inclination, where the upper blade is blunt and concave on its inner face, and the lower blade is a slightly pointed (11).

Arlt also modified the ocular 'orthoscope (for revealing the visible fundus oculi a water-box was used to neutralize the corneal curvature) invented by Johann Nepomuk Czermak (1828-1873). He made it from soft rubber and he placed glass to one side. The glass eliminated the corneal curvature and could be applied close to the eye (12).

Arlt made also his name in the field of ocular pharmacy by introducing an ointment as an analgesic and counter-irritant for ocular inflammations, such as scleritis and iritis, and for blepharospasm in phlyctenular keratitis. It was applied three to four times a day and consisted of 5 grams of unguentum hydrargyri cinerei or ammoniati and 0.5 grams of belladonnae extract. This ointment was used more in America than in Germany (13).

\section{Conclusion}

Arlt was an ingenious ophthalmologist and ocular surgeon, and an esteemed professor of ophthalmology. His name is used for the linear scar which is present in the sul- 
cus subtarsalis in Chlamydia trachomatis infection (Arlt's line), the contagious eye infection caused by Chlamydia trachomatis (Arlt's syndrome), and the keratic precipitate distributed in the wedge-shaped area on the inferior corneal endothelium (Arlt's triangle). His students were among the most significant figures in ophthalmology, such as Friedrich Wilhelm Ernst Albrecht von Graefe (1828-1870), Otto Heinrich Enoch Becker (1828-1890), August von Reuss (1841-1924), Vilmos Schulek (1843-1905), Hubert Sattler (1844-1928), Otto Bergmeister (1848-1918), Leopold Königstein (18501924), Ernst Fuchs (1851-1930), Friedrich Dimmer (1855-1926) Hans Adler (18431923) and Oskar Heifelder (dates unknown). Arlt did not live long enough to complete his autobiography, which was completed and published after his death by Otto Heinrich Enoch Becker (1).

Authors' Contributions: Conception and design: KL; Acquisition, analysis and interpretation of data: KL; Drafting the article: KL, EM, KM, EL, PLS and AC; Revising it critically for important intellectual content: $\mathrm{KL}$; Approved final version of the manuscript: KL and MMM.

Conflict of Interest: The authors declare that they have no conflict of interest.

\section{References}

1. Von Arlt F, Becker O. My life [in German]. Wiesbaden: Bergmann; 1887.
2. Von Arlt F. Dissertation. The histories of the faults of the organs of the brain about amaurosis. Observations of the author [in Latin]. Prague: Haase; 1839.

3. Von Arlt F. Care of the eyes in a healthy and diseased state calls for an attachment over eye glasses [in German]. Prague: Gerzabek; 1846.

4. Von Arlt F. Illnesses of the eye for practical physicians. Vol. 1-3 [in German]. Prague: Credner; 1850-1856.

5. Von Arlt F. About the causes and the development of myopia [in German]. Vienna: W. Braumüller; 1876.

6. Von Arlt F. Clinical presentation of diseases of the conjuctiva, cornea and chorioidea, then the iris and the ciliary body [in German]. Vienna: Braumüller; 1875.

7. Von Arlt F. Injuries of the eye and their medicolegal aspect. Philadelphia: Claxton, Remsen \& Haffelfinger; 1878.

8. Von Arlt F. Injuries to the eye from a practical and forensic point of view [in French]. Paris: Baillière; 1877.

9. Von Arlt F. Surgical Textbook for all ocular diseases. Graefe A and Saemisch T. [in German]. 1st ed. Vol. III, 1. Leipzig: Wilhelm Engelmann; 1874.

10. Beard CH. Ophthalmic surgery; a treatise on surgical operations pertaining to the eye and its appendages, with chapters on para-operative technic and management of instruments. Philadelphia: P. Blakiston's son \& co.; 1910.

11. Wood CA. A System of Ophthalmic Operations. Vol. I-II. Chicago: Cleveland Press; 1911.

12. Wood CA, editor. American Encyclopedia and Dictionary of Ophthalmology. Vol. 1. Chicago: Cleveland press; 1913-21.

13. Wood CA. A system of ophthalmic therapeutics; being a complete work on the non-operative treatment, including the prophylaxis, of diseases of the eye. Chicago: Cleveland Press; 1909. 